\title{
How "Sustainable" are Post-disaster Measures? Lessons to Be Learned a Decade After the 2004 Tsunami in the Indian Ocean
}

\author{
Christiane Stephan $^{1,2} \cdot$ Celia Norf $^{1,3} \cdot$ Alexander Fekete $^{1}$
}

Published online: 22 March 2017

(c) The Author(s) 2017. This article is an open access publication

\begin{abstract}
This article addresses the sustainability implications of post-disaster measures in the context of the 2004 Indian Ocean Tsunami by presenting an analysis of the current situations and changes in some of the affected regions. Sustainability implications of measures are captured by investigating the persistence of the social and economic living conditions in relation to post-disaster measures, and the alignment of the measures with basic environmental aspects. Based on major concepts relevant in disaster science and sustainability research, the study explored sustainability aspects of post-disaster measures implemented after the 2004 tsunami, by conducting selected interviews among the participants of the 2015 international seminar " 11 Years after the Indian Ocean Tsunami 2004" and a broader online survey. Information was sought about (1) the current state of vulnerability of the local population in the regions affected; (2) the main lessons that have been identified to improve project design and management of recovery and vulnerability reduction; and (3) project sustainability implications with respect to the state of today's vulnerability. Based on the analysis of the information on these three priority areas, selected tasks for future disaster risk management are identified, such as
\end{abstract}

Christiane Stephan

christiane.stephan@th-koeln.de

1 Institute of Rescue Engineering and Civil Protection, TH Köln University of Applied Sciences, 50679 Cologne, Germany

2 Department of Geography, Rheinische Friedrich Wilhelms Universität Bonn, 53113 Bonn, Germany

3 Department of Environmental Sociology and Technology Assessment, University of Stuttgart, 70174 Stuttgart, Germany more integrative planning and improved coordination with international organizations and local people.

Keywords Disaster risk

management $\cdot$ Recovery $\cdot$ Sustainability $\cdot$ Indian Ocean

Tsunami $\cdot$ Post-disaster measures $\cdot$ Vulnerability

\section{Introduction}

The 2004 Indian Ocean Tsunami has had fundamental short- and long-term social and ecological effects. In addition to the direct effects on the affected population and environment, organizational and structural changes are observable. These changes concern the international humanitarian aid system and approaches towards disaster risk management and recovery processes, and their possible secondary and long-term effects. Analyzing the lessons learned, specifically the lessons identified and implemented, after more than 10 years provides an important body of knowledge to reflect on what has changed and what has been achieved with regard to disaster risk science and management. Moreover, the various processes that are carried out in the humanitarian aid system need to be reviewed with respect to their consideration and implementation of sustainability criteria. This analysis is useful for researchers, humanitarian organizations, donors, and decision makers, who are involved in the activities performed in the aftermath of a disaster.

Discussing the state of vulnerability in the tsunami affected areas today requires the consideration of a complex bundle of different types of information from different sources. While in some areas activities to reduce vulnerability have been carried out successfully since the aftermath of the disaster, in other regions recovery from direct 
and indirect tsunami effects took much more time, or has not been finalized (Wong 2012; Aldrich 2010). Some positive examples stand out, however, where the reduction of vulnerability and the strengthening of local capacities has been accomplished and the situation today is described as "less vulnerable and better prepared" than before by local and international experts (USAID 2006, p. 5; Zahari et al. 2013; DW 2014).

\section{Scope of the Study}

The purpose of this article is to present findings about the current situations and changes in the regions that were affected by the 2004 tsunami. By situations and changes we mean (1) the current state of vulnerability of the local population in a respective geographic area with regard to the tsunami; (2) the changes at local and community levels that have taken place after 2004 with respect to vulnerability reduction, disaster preparedness, and resilience building; and (3) the sustainability implications, from today's perspective, of national and international projects carried out after 2004.

By analyzing current situations of vulnerability and long-term effects of post-disaster measures with a qualitative empirical approach, the aim of this article is to outline recommendations that are relevant to scientific discussions and of interest to practitioners and politicians. For this it is important to take into account the heterogeneous situations in the different regions affected by the 2004 tsunami and to explain why recovery and rehabilitation have been successful in some cases, but not or only partly successful in other cases. Finally, the lessons identified in the 2004 tsunami aftermath and the need for implementation and change according to these lessons are discussed. These are relevant for scientific and practical developments in the future.

\subsection{Underlying Conceptual Framework}

A range of different concepts and theories constitute the foundation of how risk, vulnerability, sustainability, learning, and resilience are conceptualized and addressed.

The various actors in disaster risk reduction (DRR) define and apply the concept of "risk" differently. Whereas natural science often defines risk as a primarily objective and quantitative concept, social scientists describe risk as a socially or culturally constructed and mediated concept (Kaplan and Garrick 1981; Douglas and Wildavsky 1982; Cogoy 1984; García Acosta 2005; Taylor-Gooby and Zinn 2006; Renn 2008; Egner and Pott 2010; Lupton 2013; Müller-Mahn 2013). So is risk a calculated probability that assists in predicting certain events? Is risk based on people's subjective perception? Or is risk socially and culturally constructed and negotiated? And what does each perspective mean for effective risk management and disaster risk reduction? In our understanding risk is an interdisciplinary concept that acknowledges the benefits and necessary cases for quantification, but at the same time underlines the integration of individual perception and social construction. Only then is effective disaster risk reduction possible.

The concept of "vulnerability" also encompasses a wide spectrum of possible meanings and implications. Different definitions have been discussed extensively by various authors (for example, Lewis 1999; Bankoff 2001; Few 2003; Adger 2006; Wisner et al. 2012; Birkmann 2013; Kelman et al. 2016; Weichselgartner 2016). In the context of research on disaster risk reduction, Garschagen (2014) presents an overview of different definitions of vulnerability. The specific concept of vulnerability used in this article is mainly taken from a model that has influenced scientific and practical discourse since its first publication in the book At Risk (Blaikie et al. 1994; Wisner et al. 2004). The usefulness of this so-called Pressure and Release (PAR) model for analyzing the progression of vulnerability has been widely acknowledged. The model presents vulnerability as a result of unsafe conditions within societies and the ways in which these conditions are produced through root causes such as economic and political circumstances on the one hand and dynamic pressures such as lack of skills or demographic constraints on the other hand (Wisner et al. 2004, p. 50, 52). This article focuses on social vulnerability, which can be defined as the predisposition of society and individuals to be harmed by a stressor or hazard (Wisner et al. 2004). When analyzing social vulnerability, it is essential to review the root causes in society that lead to the development of specific patterns of vulnerability (Wisner et al. 2004). The root causes include, for example, the political and economic contexts of a society. The PAR model provides one possible entry point into a holistic conceptualization of vulnerability and risk and offers the possibility to include economic and political processes at national and international levels into the analysis of vulnerability (Cannon and Müller-Mahn 2010). The PAR model is referred to not only by scientists but also by practitioners, for example, in international organizations for humanitarian aid (IFRC 2006; GCDR 2012; UNOCHA 2013; Morchain and Kelsey 2016). In this line of argumentation, vulnerability is regarded as a subjectively attributed feature of societies that cannot be described by quantitative methods alone, but is rather a highly contextual characteristic that is not readily transferable to other contexts (Kelman et al. 2015).

The concept of "sustainability" has a specific historical development and is used in many different areas ranging 
from the development of global and national policies to practical local action. With the presentation of the Brundtland Report at the UN General Assembly in 1987, sustainability has become a key paradigm in global politics and has been translated into national and regional politics subsequently (for example, Agenda 21, Rio+ conferences). The report defined sustainable development as "development that meets the needs of the present without compromising the ability of future generations to meet their own needs" (UNGA 1987, p. 43). Sustainability can be broken down into a social, an economic, and an environmental component (UNGA 2010). The political implications and the analytical setup provided by the sustainability paradigm have had wide influence on science, politics, and economics. Especially in the rise of climate change negotiations and the 2030 Agenda for Sustainable Development, the common goals and tasks of combating climate change and promoting sustainable development have been emphasized (IPCC 2014; UNGA 2015). It was also relevant for the development of the Hyogo Framework for Action (UNISDR 2005) and subsequent frameworks and concepts, linking criteria of sustainability to vulnerability assessment (Birkmann 2013). In this article, post-disaster measures are evaluated with respect to how far these measures have been carried out in a manner that enabled a sustainable reduction of social vulnerability and have had positive long-term effects on society. This article adopts the term sustainability, since it covers more than persistence, long-term effectiveness, or perpetuation of efforts. Sustainability provides specific analytical categories and a paradigmatic orientation that goes beyond disaster thinking and addresses general conditions of societal well-being.

In the context of disaster risk reduction, the concept of "learning" relates to the lessons that have been learned from past disasters and how concepts, strategies, and measures have been adapted (Jasanoff 1994; Kletz 2001; Hoffmann 2008; Egner et al. 2015). It works from the assumption that analyzing positive and negative examples from past events can help in learning and implementing changes for the future. The list of lessons learned reports published by DRR actors on different scales is long (for example, GCDR 2004; Marincioni 2007; Gautam 2010; IFRC 2010; UNISDR 2011) just as the list of conferences that hold lessons learned sessions. It is assumed that mutual learning from disasters is possible and that experience and knowledge from one country could be transferred to another country or global region (UNISDR 2011; Evely et al. 2012; IIED 2013). However, in disaster risk science, it is under controversial discussion why disaster losses continue to mount (White et al. 2001) and why new disasters occur that could have been prevented when so much knowledge is available from past disasters. Recent scientific contributions such as the volume Learning and
Calamities (Egner et al. 2015) emphasize that the logic of learning after a disaster is neither to be taken for granted nor something that historical and current empirical research confirms. The concept of learning in itself has to be deconstructed in order to understand what learning from disasters can mean on a societal level and under what circumstances it might be possible (Egner et al. 2015).

The concept of "resilience" is a buzzword in the field of disaster risk reduction. Although widely used, its meaning and effective application in DRR has been discussed indepth and critique is growing (Cannon and Müller-Mahn 2010; Pugh 2014; Kelman et al. 2016). As Reghezza-Zitt et al. (2012, paragraph 2) put it, "the polysemy seems to legitimize a semantic blur that creates theoretical and operational dead ends." However, we regard resilience as a useful tool in the discussion of disaster risk reduction. But resilience is not just a simple "bouncing back" to the status quo that systems accomplish after certain events, but also comprises a multidimensional "bounce forward" (Manyena 2009 , p. 261) that enables learning and transformation. A resilience perspective that links ecosystems with socioeconomic features (Sudmeier-Rieux and Ash 2009) allows the identification of complex interrelations between different systems and the practical strengthening of those linkages identified as important. However, Weichselgartner and Kelman (2015) accurately observe that while a resilience perspective allows for the identification and perpetuation of desirable dynamics within a system, at the same time it may perpetuate undesirable conditions. We acknowledge this ambiguous character of resilience and the necessity to clearly define the concept and illustrate its limitations.

The review of some of the conceptual perspectives in disaster risk management and risk science reveals the challenges of analyzing the long-term effects of post-disaster measures in a conceptually and practically adequate manner. It is necessary to highlight the subjectivities involved in concepts like risk, vulnerability, and resilience used in DRR measures. Regarding post-disaster measures within the spatial, sociocultural and political contexts in which they occur is a prerequisite for adequate scientific analysis. Furthermore, the long-term perspective is not regarded here as an add-on but as a necessity to adequately address questions of vulnerability and resilience. We agree with Kelman et al. (2015, p. 23) that research has to analyze "what society has done to itself (and especially what some sectors have done to other sectors) over the long-term [...] and how society might change the present state to improve in the future."

\subsection{Methodological Approach}

The analysis of the sustainability implications of post-disaster measures following the 2004 tsunami and the state of 
vulnerability today, as conceptually framed above, is based on empirical data generated through qualitative interviews and a survey linked to an international seminar on " 11 Years after the Indian Ocean Tsunami 2004 - Lessons of Disaster Recovery, Rehabilitation and Resilience," held in Cologne and Bonn, 9-13 November 2015. ${ }^{1}$ The seminar was funded by DAAD (Deutscher Akademischer Austausch Dienst/German Academic Exchange Service). Information for our study came from four sources: (1) papers on Tsunami recovery and related DRR measures presented by 19 DAAD alumni and 15 experts (researchers, journalists, and members of humanitarian aid organizations) during the seminar; (2) semi-structured interviews with four alumni; (3) a panel discussion entitled "Evaluation of the effectiveness of recovery and rehabilitation efforts after the tsunami and similar events" held with four invited experts during the seminar; and (4) a survey sent to the alumni, the participating experts, and the broader DRR community one month after the seminar.

The seminar brought together 19 DAAD alumni from eight, mostly tsunami-prone and affected nations (Indonesia, Philippines, Thailand, Myanmar, India, Sri Lanka, Peru, and Uganda), and 15 experts from Germany as well as other European and non-European countries who had been involved in Tsunami recovery and subsequent disaster-related processes as representatives of the science sector, the media or organizations of humanitarian aid or development. The DAAD alumni were selected by a scientific committee based on their scientific and practical expertise in the field of disaster recovery, rehabilitation, and resilience. The selection was based on the committee's goal to bring together representatives from different research and practical backgrounds and perspectives to foster an in-depth inter- and transdisciplinary exchange. The scientific committee was aware that due to the limited seminar scope it was not possible to include representatives from all relevant scientific disciplines and practical fields.

While many different topics and aspects of disaster recovery, rehabilitation, and resilience were brought up in the discussions, a range of set questions were asked in the four more detailed interviews. An online survey was conducted in December 2015 involving three different groups: (1) the participants of the seminar; (2) the representatives from German national and international organizations who participated in the preparation of and in the seminar; and (3) the broader DRR community accessed through the networks of the organizing institutions. The papers pre-

\footnotetext{
${ }_{1}^{1}$ https://riskncrisis.wordpress.com/events/alumni-seminars/alumniseminar-2015/.
}

sented by alumni and experts, alumni interviews, expert discussions, and survey results which had 20 respondents only reflect the views of those who actually provided experience and opinions-the accuracy of statements cannot be verified nor can statements be generalized. The views given by the seminar and survey participants may especially reflect the views of elites with access to education; views and experiences of other population groups affected could not be considered.

The empirical findings are analyzed and discussed in the light of selected literature from disaster risk science as well as grey literature reports from humanitarian and other organizations. While a structured analysis of the scientific and grey literature that addresses the sustainability implications of post-disaster measures and current vulnerabilities in the regions affected by the Indian Ocean Tsunami is beyond the scope of this article, selected publications that address shortcomings of postdisaster measures and recommendations are considered. This allows selective insight into the realities 10 years after the tsunami that are observed on the ground in the regions that were affected. This approach does not try to draw simple or uniform conclusions on the lessons identified and learned from post-disaster management following the disastrous 2004 tsunami event. Rather, the selective approach towards qualitative empirical data and literature allows the highlighting of specific vulnerabilities as a result of bottlenecks in post-disaster management and presents a complex and ambiguous picture of relevant structures and processes in disaster risk reduction.

\subsection{Research Questions}

The research questions for this study were developed in line with the main areas of interest and the conceptual background outlined above. For the interviews with the seminar participants and experts and the survey, these questions were broken down into eight parts.

1. What is the current state of vulnerability of the local population in the regions affected by the 2004 Indian Ocean Tsunami?

(a) What is the state of social vulnerability in the 2004 tsunami affected areas today?

(b) What changes have taken place since 2004 in the area of disaster preparedness and resilience building measures that influence today's vulnerability?

2. What are the main lessons learned in project design and management with respect to recovery and 
vulnerability reduction in the affected countries and regions?

(a) What are the most successful and the most unsuccessful examples of projects? What are the main factors for success or failure?

(b) What differences with regard to this (un)successfulness are observable between national programs/projects and external or international programs/projects?

(c) What lessons have been learned for projects involved in disaster recovery and disaster risk reduction after the 2004 tsunami?

3. Do the projects carried out after 2004 meet the goals of sustainability when regarding the state of vulnerability today?

(a) What differences can be observed when comparing the sustainability implications of short-term activities in the first years after the 2004 tsunami (humanitarian aid) and that of long-term activities (development cooperation, and so on)?

(b) What measures or aspects have been forgotten or sidelined after the 2004 tsunami and should be considered for disaster recovery and rehabilitation from future disasters?

(c) In how far are ideas of "sustainable development" considered in the DRR activities as well, or are they sidelined by DRR foci?

\section{Sustainability Implications of Post-disaster Measures}

Five years after the 2004 Indian Ocean Tsunami, Margareta Wahlström, the Special Representative of the United Nations Secretary-General for Disaster Risk Reduction, evaluated the results of the collective efforts for recovery positively: "The affected countries and communities have largely recovered, and warning systems are now in place, not just for tsunamis, which are relatively rare, but also linked to those for tropical cyclones, storms, and floods" (UNISDR 2009, p. 1). This evaluation of recovery and other activities by the Special Representative of the UN might have had the intention to highlight the significant efforts and positive outcomes of disaster relief and recovery, thereby promoting high levels of motivation of all the involved actors to continue creating the necessary conditions for long-term vulnerability reduction. But the generality of the statement cannot do justice to the variations of recovery and the effects created in the different nations and parts of societies. From a scientific point of view it is important to review how firsthand information and scientific literature 11 years after the 2004 Indian Ocean Tsunami describe and evaluate the situation on the ground today.

\subsection{Vulnerability Today}

In the case of Banda Aceh, Indonesia, the researchers from the region that participated in the seminar confirmed that vulnerability of the population towards a tsunami or other disaster events linked to natural hazards seems to be lower today than it was in 2004 (Interview 1 with DAAD alumni from Indonesia, researcher at Tsunami Disaster and Mitigation Research Center, 11 November 2015). Many programs have been carried out that have addressed the rehabilitation and improvement of infrastructures as well as better preparation towards tsunamis in the future. With respect to Wisner et al.'s (2004) Pressure and Release Model this means that unsafe conditions in the form of a fragile physical environment as well as the limitations in public actions as important factors of social vulnerability towards natural disasters can thus be reduced. Nevertheless, as the case of the 2012 earthquake in Banda Aceh showed, for early warning to be a fully functional system a lot more technical capacity building and awareness raising in the larger society are needed. Low acceptance of evacuation buildings is also an issue that has to be addressed to be able to implement a disaster risk management strategy that is known to and accepted by larger parts of the population. Risk is in part socially constructed and risk management strategies need to acknowledge social perceptions and processes to achieve wide public acceptance (Renn 2008).

In the case of Sri Lanka, the participants and experts from the region confirmed that vulnerability in the coastal areas is still very high and the various resettlement schemes carried out as part of relief activities have in many cases resulted in an even higher marginalization of local people. This marginalization is closely connected with limitations in access to power and resources and is one of the root causes of social vulnerability (Wisner et al. 2004). The question raised during the seminar is who is in charge today of taking responsibility for the unfavorable living and economic conditions that population faces as a result of shortcomings in the reconstruction and resettlement of people in the disaster response phase. With the ending of the time frame of the disaster response phase, international organizations hand projects over to national governments or local communities. While in general this is in line with principles of ownership and empowerment, from the 
perspective of the Sri Lankan scientists this sometimes results in passing on not only the responsibility for projects, but the mistakes made as well.

The seminar participants discussed the issue on the assumption that root causes of vulnerability have to be regarded and taken into account more thoroughly for a proper analysis. By reviewing the 2004 tsunami disaster through the lens of the Pressure and Release Model (Wisner et al. 2004), the importance of the regional and local contexts and the various dimensions that influence a disaster became visible during the seminar. This holds true when talking about the vulnerability as it was in 2004, when the tsunami hit, and for the situation today. As Kelman et al. (2015) point out vulnerability is a highly contextual characteristic and altered due to changes of the larger context and political decisions, as well as due to changes in the environment and livelihood conditions on the ground.

Thinking about the possible negative and positive effects a disaster can have in local contexts, the participants raised the question whether it is enough to reestablish the livelihoods of the affected population in the same conditions as before, or whether there is a responsibility to improve livelihood conditions and reduce vulnerabilities in the future. The question whether the goal of vulnerability reduction has been achieved in the aftermath of the 2004 Indian Ocean Tsunami thus has many answers. As selected examples presented below underline, there are positive cases where people are less vulnerable and better prepared today than before 2004, but there are also unintended negative cases of secondary effects of recovery and reconstruction measures, that have resulted in increased vulnerabilities of population.

\subsection{Lessons Identified, Learned, and to Be Learned}

When thinking about lessons learned, it is important to ask how people, societies, or governments learn. Relevant also for the case of disaster risk reduction is the underlying conceptual question, raised for example by Egner et al. (2015), whether the adaptation of one's body of knowledge after a disaster is already learning or whether learning happens only when changes occur in behavior or in the adaptation of policies. It is crucial to determine what lessons have been identified and what lessons have been learned and implemented. The differentiation between the identification of lessons to be learned and their implementation is paramount to distinguishing between knowledge and actions.

The array of lessons and examples in the field of DRR is diverse. Different examples from local situations after the 2004 tsunami emerged from the interviews and discussions during the seminar. In some examples experience from the past has not resulted in an improved performance towards recent disaster events.

\subsubsection{Positive Examples}

In Banda Aceh, Indonesia, the Agency for Rehabilitation and Reconstruction (BRR-Badan Rehabilitasi dan Rekonstruksi) was established after the 2004 tsunami to coordinate donor agencies in order to achieve sound and successful reconstruction in the affected areas. From the point of view of the interview partner, this agency is a positive example that can prevent the mismatch of donor activities and requirements on the ground (Interview 1, 11 November 2015). The importance of local institutions for tackling dynamic pressures is also highlighted by the Pressure and Release Model (Wisner et al. 2004).

Another positive example-presented during the seminar in the short documentary film "Buffer Zone. Sri Lanka - 10 Years After the Tsunami" by Gabriela Neuhaus and Angelo Scudeletti (2014)—was the initiative of a private person in Sri Lanka. As a Swiss national who owned a house in a village in Sri Lanka, the man coordinated collaborative efforts with villagers to reconstruct the house of every family on the same spot it had been located before the 2004 tsunami. Work was carried out according to his own plans and with the villagers' labor. This initiative was presented by the filmmakers as one of very few examples of sustainable reconstruction and ownership of post-tsunami actions.

\subsubsection{Negative Examples}

One example by a participant underlined the failure of the early warning system during the 2012 earthquake in the Banda Aceh region. The early warning message arrived, but it was not passed on successfully to the local level because the responsible staff did not know the technical procedure of how to set the siren. Another fact was that after evacuation was ordered, most people did not go to the evacuation building because there was no trust that this building was safe (Interview 1, 11 November 2015).

An example from Thailand illustrates that some donor agencies did not know the cultural context when carrying out rehabilitation measures. In this project people were trained in baking bread, although bakeries do not traditionally exist in Thailand and bread is consumed mainly by tourists but not by local people. As one interview-partner emphasized, "I think the donors should from the beginning on have contact with the communities and then have the communities more engaged in the planning or at the start of the process" (Interview 2 with DAAD alumni from Thailand, expert in community-based disaster management, 11 November 2015). 
An additional challenge visible in Thailand is what could be called "fragmented recovery." This refers to the concept of "fragmented development" introduced by geographer Fred Scholz (2002) to describe unequal economic development inside one country or region due to the promotion of single-industry development, disregarding the promotion of other economic branches. As an example of "fragmented recovery" one participant described that all the tourist areas have been well reestablished in Thailand and have the same or even better infrastructure and services than before 2004. In coastal areas far from the tourist regions, where local people used to work as fishermen, the inhabitants are still struggling to make their living. Many of them have shifted their livelihood from fishing to agriculture, but this does not happen without risks and is a long-term process that has little support from the national government (Interview 2, 11 November 2015).

The topic of lessons learned was discussed during the seminar's roundtable talks between scientists and practitioners. Table 1 highlights the range of topics and opinions and lists some quotes of the participants.

\subsection{Results of the Study}

To summarize the findings gained throughout the seminar and the survey, an overview of the main aspects mentioned by the experts from different scientific, national, and organizational backgrounds is presented in Table 2. The range of arguments is considerable given the range of different people with specific viewpoints and organizational affiliations. This presentation was chosen deliberately to present the multiplicity of perspectives and approaches in a direct way. The intention is to create a foundation for a holistic approach towards future design of strategies that acknowledge the social construction of risk, help to reduce vulnerability, and meet criteria of sustainability.

The need for effective dissemination of relevant knowledge gained in research and practical action was stressed. Given that vulnerability is regarded as a subjectively attributed feature of societies (Kelman et al. 2015), it is crucial to understand the specific social and cultural contexts of locations before implementing any kind of disaster risk reduction measures. Research findings need to be disseminated in an understandable way at all levels (with the help of electronic devices, for example, or orally).

With respect to the organization of aid and relevant policies, the need for an effective distribution of tasks and the design of efficient financial plans was highlighted. The assignment of donor money to specific situations did not prove to be useful in the aftermath of the 2004 tsunami, because unnecessary investments were made in some cases and necessary investments could not be made in other cases. Within the context of technological measures, the

Table 1 Round table participant quotes on the topic of lessons learned from the 2004 Indian Ocean Tsunami

\section{Selected quotes on the topic of lessons learned stated during the round table talk held at the DAAD Alumni Seminar, 11 November 2015}

"Why didn't we learn from past incidents? Where did the lessons learned from past projects go?"

"What is needed is a people-centred risk evaluation for adequate early warning systems."

"Time is an essential factor. Everybody thinks there is not enough time to plan properly. But in the case of Sri Lanka, after eight weeks, people were relatively safe concerning their basic life. Then planning should come in. An open discussion among all."

"A catastrophe happens in a country. Each country has a context. This context has to be regarded. When you come from outside of the country, you have to take it into account."

"We need to focus on object-based approaches rather than needs-based approaches.

Because there are no capacities to improve everything."

"We as different humanitarian aid organizations have to work more on coordination, on joint advocacy and on networking. Because otherwise we will not be able to achieve this overall goal of enhancing resilience."

"We have to build a system of structure and culture. Without it, from end to end, we could never achieve any increase in resilience." 
Table 2 Summary of results of the analysis of the responses from the expert interviews and the survey conducted during and after the 2015 seminar "11 Years after the Indian Ocean Tsunami 2004—Lessons of Disaster Recovery, Rehabilitation and Resilience"

\section{Relevant knowledge and dissemination}

- Need for project managers to understand context knowledge before implementing any kind of disaster risk reduction measures.

- Effective disaster risk management that not just understands (social) context but also accepts it and does not only transfer solutions from one context to the other.

- Importance of disseminating research findings at all levels (through electronic devices, for example, or orally).

- Need to present scientific findings in a way that is understandable for all involved parties (politicians, local communities, and so on).

\section{Organization of aid and relevant policies}

- Need for separation of working fields and distribution of tasks to specialists accompanied with continuous exchange and communication within and across fields.

- Need to institutionalize disaster preparedness by involving all relevant actors at all different scales (scientists, technicians, politicians, public) and levels (international, national, regional and local) in the project planning from the beginning.

- Need for effective long-term, comprehensive planning and participatory approaches and incorporation of lessons-learned from past-projects into planning process.

- Government should create a disaster response blueprint available to everyone that could prepare communities for disaster, minimalize the effects of disaster, and allow for fast economic revitalization.

- Inclusion of costs for (long-term) capacity building in financial plans.

- No assignment of money donations to specific hazards or situations in order to prevent unnecessary investments.

- Need to understand and reflect intentions of donors before accepting their help.

- Discussion of donors' length of stay and determination of responsibility after donors leave.

\section{Implementation of technological measures}

- Follow-up on maintenance issues and effective capacity building and awareness raising, not only in focus country but also in other countries facing the same risk.

- Need to improve awareness and preparedness regarding early warning (through methods, for example, radio, and so on, and education on how to react to warnings and what to do), as technical component of early warning is also linked to social and cultural aspects.

- Maintenance of technical components of early warning in the long term.

- Increased construction of sand dunes combined with green belts as one of the most effective hybrid infrastructure design features to help protect coastal areas from tsunamis.

4. Participation, property issues, and legal empowerment

- Need for provincial government support.

- Consideration of social networks in reconstruction planning and resettlement decisions.

- Importance of building social ties. Building construction in relocation sites should take into account social behavior.

- Bottom-up exchange between the government and prospective relocatees about vulnerabilities and opportunities for future development, and involvement of possible relocatees in decision on site selection, design, material, and so on.

- Need for legal terms for settlers. 
importance of their long-term maintenance was emphasized, as well as the necessity of linking early warning systems to public education and awareness raising, so that people learn how to react in the case of an early warning.

With regard to participation, property issues, and legal empowerment, the value of the implementation of participatory approaches that foster long-term and trustful cooperation between all actors involved was underlined. This emphasis is in line with the Pressure and Release Model (Wisner et al. 2004) that highlights the need for local institutions to achieve decreasing social vulnerability.

\section{Synthesis of Results and Future Disaster Risk Management Priorities}

A review of measures carried out from a time perspective more than 10 years after a disaster event poses challenges. Given the fact that the 2004 Indian Ocean Tsunami affected a range of different countries, accessing relevant and representative information is difficult. The interest of this study in the evaluation of disaster interventions from a long-term perspective, however, stimulated the design of an approach that reveals several relevant aspects for future disaster risk management and evaluation of measures. Starting from the intense exchange of experiences, information, and approaches during the seminar, it became clear that a more comprehensive scientific analysis was necessary. The main results of this analysis are linked here to findings of other authors in the scientific literature, as well as grey literature (reports of government agencies, humanitarian organizations, and so on). In the form of a synthesis different findings are integrated and answer the main research questions of this study. The four identified priority areas (Fig. 1) are discussed in the following. It is these areas researchers, actors at different political levels, as well as aid organizations need to address more thoroughly in the future. The design of projects for disaster prevention and the long-term reduction of vulnerabilities can take crucial information from the lessons identified from the 2004 Indian Ocean Tsunami and subsequent measures and policies, the lessons learned and the lessons still to be learned and implemented. Figure 1 presents a selection of key tasks necessary for the design of suitable strategies for the future with the intention of stimulating further discussion and critical reflection.

The analysis of the current state of vulnerability of the local population in regions affected by the 2004 tsunami does not lead to a homogenous picture. Various authors (Larsen et al. 2010; Frankenberg et al. 2013; Kapadia 2014; Løvholt et al. 2014; Siagian et al. 2014) indicate that data generation, monitoring, and access to information is still a major task at national as well as at international levels.
Qualitative data from our interviews also indicate that the states of vulnerability differ significantly from one region or nation to another. Moreover, scientific definitions (Garschagen 2014) as well as perceptions of vulnerability differ considerably. It has been possible, however, to determine key aspects of today's vulnerability in the regions affected by the 2004 Indian Ocean Tsunami. The compilation of relevant knowledge and the adequate dissemination of information and knowledge need to be a major priority for future DRR strategies.

The second priority area concerns the organization of aid and relevant policies. Some of the lessons identified and to be implemented directly concern the design and management of projects for recovery and vulnerability reduction. The need for adequate organization and financing of short- and long-term measures was emphasized by interview partners as well as many authors of reports and scientific papers (GURD 2005; Bennet et al. 2006; Flint and Goyder 2006; Telford and Cosgrave 2007; Twigg 2015). The interview partners proposed the development of financial mechanisms that can channel donations and provide resources independent from any one specific hazard event (see also UNICEF 2009). Financial plans should also include costs for capacity building and other long-term measures. Another key requirement for future post-disaster management is to take into account politics and power effects involved in aid and recovery measures. Limited access to power and ideological political systems can be major root causes of social vulnerability (Wisner et al. 2004). While political processes of peace-building in conflict regions can enhance recovery efforts, as examples from Aceh in Indonesia have shown (Gaillard et al. 2008), the effective organization of aid can also be hindered by power relations within societies (Scheper et al. 2006). As examples from Sri Lanka show, relations of inequality between different social groups can substantially influence the access to support from recovery programs (Kapadia 2014). Besides challenges faced by humanitarian actors in affected countries, an important lesson to be learned by the organizations is the need to overcome disparities between "the stated policies of international humanitarian actors and the operational realities" (Kapadia 2014, p. 41).

As a third priority area, the implementation of technological measures was identified. While significant progress has been made concerning early warning systems (as examples from Indonesia and Sri Lanka show), there is still a severe lack of well-designed systems in many tsunami-exposed regions (Løvholt et al. 2014). Some authors argue for a "people centered" tsunami early warning system (Gebert and Post 2010) that links technological aspects of a warning with the social 
Fig. 1 Priority areas and selected tasks for future disaster risk management. Source Authors

\section{Relevant knowledge and dissemination}

$\begin{array}{ll}\text { Gain access to and respect context } & \text { Apply vulnerability information in a } \\ \text { knowledge } & \text { systematic way } \\ \text { Communicate research findings in an } & \text { Elaborate a comprehensive profile of social } \\ \text { understandable way } & \text { vulnerability }\end{array}$

Organization of aid and relevant policies

Include costs for (long-term) capacity

building in financial plans

Build up donation systems independent

from specific hazard events
Ensure transparency of donor intentions Reflect on politics and power effects involved in aid and recovery measures Reflect on disparities between operational realities and policies of organizations

\section{Implementation of technological measures}

Identify bottlenecks in technologies concerning evacuation and early warning Design hybrid Eco-DRR measures
Ensure maintenance of technical components in the long term

Invest in capacity building and awareness raising

\section{Participation, property issues and legal empowerment}

Emphasize social networks in decisions on reconstruction and resettlement

Consider pre-existing social inequalities, including land and property rights
Complement consultative forms post-disaster reconstruction processes with legal empowerment of local groups response system. Bottlenecks have been identified for various countries related to evacuation routes and disaster zoning as part of urban planning (Suppasri et al. 2015). Tasks such as evacuation reveal the need to firmly link the improvements in technological measures with capacity building to ensure the maintenance of devices for communication (for example mobile phones, radios, loudspeaker systems), the sharing of responsibilities for their operation in the case of a disaster, and reflection on the appropriateness and acceptance of proposed technological measures and procedures. A transdisciplinary approach for implementing technological measures that involves researchers of different disciplines (engineers, social as well as natural scientists) and small and medium enterprises was discussed during the seminar. This transdisciplinary approach is recommended as an important step for improving the sociotechnological nexus of humanitarian aid and long-term vulnerability reduction.
The fourth priority area concerns issues of participation, property rights, and legal empowerment. Interview partners emphasized that humanitarian actors need to take into account existing social networks as well as inequalities, including issues of access to land and property. Empirical research in the affected regions shows that land tenure is a critical issue for vulnerability reduction (Massmann and Wehrhahn 2014). Linked to this, functional strategies are needed for community participation in decision-making processes that are not limited to post-disaster phases but implemented in day-to-day politics, as argued for the case of Sri Lanka (Khazai et al. 2006). Attavanich et al. (2015, p. 485) call for the "empowerment of marginalized people through a legal framework that recognizes their longestablished customary rights, respects their cultural heritage and considers both their immediate and long-term livelihood needs." Addressing questions of sustainability in disaster risk reduction inevitably requires taking seriously the need for legal empowerment. Mainstreaming this 
empowerment in long-term participatory DRR processes is regarded as a complex but crucial task in order to strengthen equity and reduce root causes of vulnerability in heterogeneous societies.

The critical reflection of the topics and tasks presented in Fig. 1 allows addressing the issue of the sustainability implications of the post-disaster measures carried out following the 2004 Indian Ocean Tsunami. While sustainability implications as a criterion in the evaluation of measures and projects so far lacks a clear definition, it is of crucial importance that it be clearly defined in the future. Integrating sustainability into DRR, understanding sustainability not as a parameter for development, but as a paradigm that includes integrative processes and participation, is the direction we consider essential.

\section{Conclusion}

This article presents findings and reflections about current situations and changes in selected regions that were affected by the 2004 Indian Ocean Tsunami. The summary of the findings highlights relevant tasks for the improvement of disaster risk management. A major lesson identified and to be learned is that the reduction of vulnerabilities needs to take into account the different cultural, economic, environmental, political, and social characteristics of a region. For a sustainable humanitarian aid system improved coordination is necessary. Empowerment of national governments and coordination with international organizations is important to prevent the clash of contradicting logics and philosophies among humanitarian organizations in the future.

"Sustainability" has been identified as a major issue that needs to be integrated into disaster risk management. We understand sustainability as both (1) the persistence of the social and economic living conditions in relation to post-disaster measures; and (2) the alignment of the measures with basic environmental aspects. The consideration of sustainability and sustainable development in frameworks such as the Hyogo or the Sendai Frameworks (UNISDR 2005, 2015) is an important milestone for reducing social vulnerabilities in the long term. It is necessary, however, to clearly define the vague concept of sustainability and to break it down into tangible measures in DRR projects and into consistent evaluation criteria. Sustainability is a crucial concept to be included into vulnerability reduction because it can reveal the shortand long-term side-effects specific interventions have on social groups and geographical regions. It is important to have scientists and practitioners from affected countries remind us that a long-term, holistic, and interdisciplinary perspective is needed. Just as climate change adaptation spurs synergies with DRR, sustainability as a goal could help design communities that persist, endure, and thrive, but are also resource-sensitive. This perspective not only helps to better understand current situations in countries like Indonesia, Thailand, and Sri Lanka but also helps science and practice to design disaster risk measures for the future that are in line with ideas of social and ecologic sustainability.

Open Access This article is distributed under the terms of the Creative Commons Attribution 4.0 International License (http://crea tivecommons.org/licenses/by/4.0/), which permits unrestricted use, distribution, and reproduction in any medium, provided you give appropriate credit to the original author(s) and the source, provide a link to the Creative Commons license, and indicate if changes were made.

\section{References}

Adger, W.N. 2006. Vulnerability. Global Environmental Change 16(3): 268-281.

Aldrich, D.N. 2010. Separate and unequal: Post-tsunami aid distribution in Southern India. Social Science Quarterly 91(5): 1369-1389.

Attavanich, M., A. Neef, H. Kobayashi, and T. Tachakitkachorn. 2015. Change of livelihoods and living conditions. In Recovery from the Indian ocean tsunami: A ten-year journey, ed. R. Shaw, 471-486. Tokyo: Springer.

Bankoff, G. 2001. Rendering the world unsafe: "vulnerability" as western discourse. Disasters 25(1): 19-35.

Bennet, J., W. Bertrand, C. Harkin, S. Samarasinghe, and H. Wickramatillake. 2006. Coordination of international humanitarian assistance in tsunami-affected countries. London: Tsunami Evaluation Coalition. http://www.alnap.org/resource/3530. Accessed 21 Nov 2016.

Birkmann, J. 2013. Measuring vulnerability to promote disasterresilient societies and to enhance adaptation: Conceptual frameworks and definitions. In Measuring vulnerability to natural hazards: Towards disaster resilient societies, 2nd edn., ed. J. Birkmann, 9-79. Tokyo and New York: United Nations University.

Blaikie, P., T. Cannon, I. Davis and B. Wisner. 1994. At risk: Natural hazards, people's vulnerability, and disasters. London and New York: Routledge.

Cannon, T., and D. Müller-Mahn. 2010. Vulnerability, resilience and development discourses in context of climate change. Natural Hazards 55(3): 623-635.

Cogoy, M. 1993 [1984]. Risk and acceptance of technology-political decisions (Risiko und Akzeptanz technologiepolitischer Entscheidungen). In Risk and Society (Risiko und Gesellschaft), ed. G. Bechmann, 145-165. Opladen: Westdeutscher Verlag.

DW (Deutsche Welle). 2014. Ten years after the tsunami: How has Aceh changed? Interview of Kira Kay by Gabriel Dominguez. http://www.dw.com/en/ten-years-after-the-tsunami-how-hasaceh-changed/a-18149958. Accessed 21 Nov 2016.

Douglas, M., and A. Wildavsky. 1982. Risk and culture: An essay on the selection of technical and environmental dangers. Berkeley: University of California Press.

Egner, H., and A. Pott. 2010. Geographic risk research. On the construction of spatialized risks and securities (Geographische Risikoforschung. Zur Konstruktion verräumlichter Risiken und Sicherheiten). Stuttgart: Franz Steiner Verlag. 
Egner, H., M. Schorch, and M. Voss. 2015. Introduction: Can societies learn from calamities? In Learning and calamities: Practices, interpretations, patterns, ed. H. Egner, M. Schorch, and M. Voss, 1-23. New York and Milton Park: Routledge.

Evely, A.C., I. Fazey, L.C. Stringer, and M.S. Reed. 2012. Designing knowledge exchange for resilience: How people view and construct knowledge matters. http://sustainable-learning.org/ wp-content/uploads/2012/01/Evely-et-al-2012-SustainableLearning-Working-Paper-Series-No.-2.pdf. Accessed 21 Nov 2016.

Few, R. 2003. Flooding, vulnerability and coping strategies: Local responses to a global threat. Progress in Development Studies 3(1): 43-58.

Flint, M., and H. Goyder. 2006. Funding the tsunami response: A synthesis of findings. London: Tsunami Evaluation Coalition. http://www.alnap.org/resource/3534. Accessed 21 Nov 2016.

Frankenberg, E., B. Sikoki, C. Sumantri, D. Thomas, and W.Suriastini. 2013. Education, vulnerability, and resilience after a natural disaster. Ecology and Society 18(2): Article 16.

Gaillard, J.C., E. Clavé, and I. Kelman. 2008. Wave of peace? Tsunami disaster diplomacy in Aceh, Indonesia. Geoforum 39(1): 511-526.

García Acosta, V. 2005. Risk as a social construct and the social construction of risks (El riesgo como construcción social y la construcción social de riesgos). Desacatos 19: 11-24.

Garschagen, M. 2014. Risky change? Vulnerability and adaptation between climate change and transformation dynamics in Can Tho City, Vietnam. Stuttgart: Steiner.

Gautam, D. 2010. Good practices and lessons learned: Disaster risk reduction through schools. Kathmandu: Actionaid/DFID.

Gebert, N., and J. Post. 2010. The role of integrating natural and social science concepts for risk governance and the design of people-centred early warning systems: Case study from the German-Indonesian Tsunami EarlyWarning System Project (GITEWS). Geophysical Research Abstracts 12, EGU20103534, EGU General Assembly.

GCDR (German Committee for Disaster Reduction). 2004. Flood risk reduction Germany: Lessons learned from the 2002 Disaster in the Elbe Region. http://www.dkkv.org/fileadmin/user_upload/ Veroeffentlichungen/Publikationen/DKKV_29_Lessons_. Learned.pdf. Accessed 21 Nov 2016.

GCDR (German Committee for Disaster Reduction). 2012. Detecting disaster root causes: A framework and an analytic tool for practitioners. http://www.preventionweb.net/files/globalplat form/entry_bg_paper $\sim$ studydetectingdisasterrootcausesweb. pdf. Accessed 21 Nov 2016.

GURD (Groupe Urgence, Réhabilitation, Développement). 2005. Evaluation of French public aid to countries affected by the earthquake and tsunami on 26 December 2004 and the earthquake in March 2005 (Evaluation de laide publique francaise aux pays touches par le seisme et le tsunami du 26 Decembre 2004 et le seisme du Mars 2005). Rapport de mission "Indonesie". http:// www.alnap.org/resource/3319. Accessed 23 Nov 2016.

Hoffmann, M. 2008. Learning from catastrophes. After the accidents from Harrisburg, Seveso and Sandoz (Lernen aus Katastrophen. Nach den Unfällen von Harrisburg, Seveso und Sandoz). Berlin: Edition Sigma.

IFRC (International Federation of Red Cross and Red Crescent Societies). 2006. What is VCA? An introduction to vulnerability and capacity assessment. http://www.ifrc.org/Global/Publica tions/disasters/reducing_risks/VCA/whats-vca-en.pdf. Accessed 21 Nov 2016.

IFRC (International Federation of Red Cross and Red Crescent Societies). 2010. Building capacity in disaster risk management: Red Cross Red Crescent lessons learned in the Democratic
People's Republic of Korea. http://www.ifrc.org/Global/Publica tions/disasters/reducing_risks/201300-North-Korea-Case-Study. pdf. Accessed 2 Feb 2016.

IIED (International Initiative for Environment and Development). 2013. Lessons from Bangladesh for a post-Sandy New York. http://www.iied.org/lessons-bangladesh-for-post-sandy-newyork. Accessed 2 Feb 2016.

IPCC (Intergovernmental Panel on Climate Change). 2014. Climate change 2014: Impacts, adaptation, and vulnerability. Part A: Global and sectoral aspects. Contribution of Working Group II to the Fifth Assessment Report of the Intergovernmental Panel on Climate Change, ed. C.B. Field, V.R. Barros, D.J. Dokken, K.J. Mach, M.D. Mastrandrea, T.E. Bilir, M. Chatterjee, K.L. Ebi, Y.O. Estrada, R.C. Genova, B. Girma, E.S. Kissel, A.N. Levy, S. MacCracken, P.R. Mastrandrea, and L.L. White, 1-32. Cambridge and New York: Cambridge University Press.

Jasanoff, S. (ed.). 1994. Learning from disaster: Risk management after Bhopal. Philadelphia: University of Pennsylvania Press.

Kapadia, K. 2014. Sri Lankan livelihoods after the tsunami: Searching for entrepreneurs, unveiling relations of power. Disasters 39(1): $23-50$.

Kaplan, S., and B.J. Garrick. 1993 [1981]. The quantitative determination of risk (Die quantitative Bestimmung von Risiko). In Risk and Society (Risiko und Gesellschaft), ed. G. Bechmann, 91-124. Opladen: Westdeutscher Verlag.

Kelman, I., J.C. Gaillard, J. Lewis, and J. Mercer. 2016. Learning from the history of disaster vulnerability and resilience research and practice for climate change. Natural Hazards 82(1): 129-143.

Kelman, I., J.C. Gaillard, and J. Mercer. 2015. Climate change's role in disaster risk reduction's future: Beyond vulnerability and resilience. International Journal of Disaster Risk Science 6(1): 21-27.

Khazai, B., F. Guillermo, J.C. Ingram, C. Rumbaitis del Rio, P. Dias, R. Dissanayake, R. Chandratilake, and S.J. Kannaf. 2006. PostDecember 2004 Tsunami reconstruction in Sri Lanka and its potential impacts on future vulnerability. Earthquake Spectra 22(S3): S829-S844.

Kletz, T. 2001. Learning from accidents, 3rd edn. Oxford: Gulf Professional Publishing.

Larsen, R.K., F. Thomalla, and F. Miller. 2010. Learning to build resilient coastal communities: Post-tsunami recovery in Sri Lanka and Indonesia. In Tropical deltas and coastal zones: Food production, communities and environment at the land-water interface, ed. C.T. Hoanh, B.W. Szuster, S. Kam, A.M. Ismail, and A.D. Noble, 350-366. Wallingford, Cambridge: CAB International.

Lewis, J. 1999. Development in disaster-prone places: Studies of vulnerability. London: Intermediate Technology Publications.

Løvholt, F., N.J. Setiadi, J. Birkmann, C.B. Harbitz, C. Bach, and N. Fernando. 2014. Tsunami risk reduction - are we better prepared today than in 2004? International Journal of Disaster Risk Reduction 10: 127-142.

Lupton, D. 2013. Risk, 2nd edn. London: Routledge.

Manyena, B. 2009. Disaster resilience in development and humanitarian interventions, Doctoral dissertation. University of Northumbria, Newcastle, UK. http://nrl.northumbria.ac.uk/661/ 1/manyena.siambabala_phd.pdf. Accessed 26 Nov 2016.

Marincioni, F. 2007. Information technologies and the sharing of disaster knowledge: The critical role of professional culture. Disasters 31(4): 459-476.

Massmann, F., and R. Wehrhahn. 2014. Qualitative social vulnerability assessments to natural hazards: Examples from coastal Thailand. Journal of Integrated Coastal Zone Management 14(1): 3-13. 
Morchain, D., and F. Kelsey. 2016. Finding ways together to build resilience: The vulnerability and risk assessment methodology. Oxford: Oxfam GB.

Müller-Mahn, D. (ed.). 2013. The spatial dimension of risk: How geography shapes the emergence of riskscapes. London: Routledge.

Neuhaus, G., and A. Scudeletti. 2014. Buffer zone. Sri Lanka 10 years after the Tsunami. Swissfilms. http://www.swissfilms. ch/de/film_search/filmdetails/-/id_film/2146991400. Accessed 2 February 2017.

Pugh, J. 2014. Resilience, complexity and post-liberalism. Area 46(3): 313-319.

Reghezza-Zitt, M., S. Rufat, G. Djament-Tran, A. Le Blanc, and S. Lhomme. 2012. What resilience is not: Uses and abuses. Cybergeo 621: 1-23.

Renn, O. 2008. Concepts of risk: An interdisciplinary review - Part 2: Integrative approaches. GAIA - Ecological Perspectives for Science and Society 17(2): 196-204.

Scheper, E., A. Parakrama, and S. Patel. 2006. Impact of the Tsunami response on local and national capacities (Joint evaluation No. 2). With contributions from Tony Vaux. London: Tsunami Evaluation Coalition. http://www.alnap.org/resource/3532. Accessed 2 Feb 2017.

Scholz, F. 2002. The theory of "fragmenting development (Die Theorie der "fragmentierenden Entwicklung"). Geographische Rundschau 54(10): 6-11.

Siagian, T.H., P. Purhadi, S. Suhartono, and H. Ritonga. 2014. Social vulnerability to natural hazards in Indonesia: Driving factors and policy implications. Natural Hazards 70(2): 1603-1617.

Sudmeier-Rieux, K., and N. Ash. 2009. Environmental guidance note for disaster risk reduction: Healthy ecosystems for human security, revised edn. Gland, Switzerland: IUCN.

Suppasri, A., K. Goto, A. Muhari, P. Ranasinghe, M. Riyaz, M. Affan, E. Mas, M. Yasuda, and F. Imamura. 2015. A decade after the 2004 Indian Ocean Tsunami: The progress in disaster preparedness and future challenges in Indonesia, Sri Lanka, Thailand and the Maldives. Pure and Applied Geophysics 172(12): 3313-3341.

Taylor-Gooby, P., and J.O. Zinn. 2006. Risk as an interdisciplinary research area. In Risk in social science, ed. P. Taylor-Gooby, and J.O. Zinn, 20-53. Oxford: Oxford University Press.

Telford, J., and J. Cosgrave. 2007. The international humanitarian system and the 2004 Indian Ocean earthquake and tsunamis. Disasters 31(1): 1-28.

Twigg, J. 2015. Disaster risk reduction. Good practice review 9. http://odihpn.org/resources/disaster-risk-reduction/. Accessed 26 Nov 2016.

UNGA (United Nations General Assembly). 1987. Report of the world commission on environment and development: Our common future. http://www.un-documents.net/wced-ocf.htm. Accessed 12 Jan 2017.

UNGA (United Nations General Assembly). 2010. Implementation of Agenda 21, the programme for the further implementation of Agenda 21 and the outcomes of the World Summit on Sustainable Development. http://repository.un.org/bitstream/handle/11176/ 257434/A_RES_60_193-EN.pdf?sequence=3\&isAllowed=y. Accessed 26 Jan 2017.

UNGA (United Nations General Assembly). 2015. Draft outcome document of the United Nations summit for the adoption of the post-2015 development agenda. http://www.un.org/ga/search/ view_doc.asp?symbol=A/69/L.85\&Lang=E. Accessed 26 Jan 2016.
UNICEF (United Nations Children's Fund). 2009. Children and the 2004 Indian Ocean Tsunami: Evaluation of UNICEF's programmes in Aceh, Indonesia. Child protection report. New York: UNICEF.

UNISDR (United Nations International Strategy for Disaster Reduction). 2005. Hyogo framework for action 2005-2015: Building the resilience of nations and communities to disasters. http:// www.unisdr.org/files/1037_hyogoframeworkforactionenglish. pdf. Accessed 23 Feb 2017.

UNISDR (United Nations International Strategy for Disaster Reduction). 2009. Five years after the Indian Ocean Tsunami - are we better prepared and more resilient to disasters? http://www. preventionweb.net/files/12158_UNISDRPR242009.pdf. Accessed 23 Feb 2017.

UNISDR (United Nations International Strategy for Disaster Reduction). 2011. Reflections, lessons learned and recommendations for action for peer-to-peer learning scale up and operation for the making cities resilient campaign. http://www.unisdr.org/ campaign/resilientcities/assets/documents/city2city/BTO-SriLanka-mayor-study-visit-to-San-Francisco-final.pdf. Accessed 26 Jan 2017.

UNISDR (United Nations International Strategy for Disaster Reduction). 2015. Sendai framework for disaster risk reduction 20152030. http://www.unisdr.org/files/43291_sendaiframeworkfordr ren.pdf. Accessed 23 Feb 2017.

UNOCHA (United Nations Office for the Coordination of Humanitarian Affairs). 2013. OCHA in 2014 \& 2015: Plan and budget. https://docs.unocha.org/sites/dms/Documents/OCHA\%20in\% 202014-15\%20vF\%2072\%20dpi\%20single\%20WEB.pdf. Accessed 26 Jan 2017.

USAID (United States Agency for International Development). 2006. Lessons learned in recovery post-tsunami relief and reconstruction for sustainable coastal development. Proceedings report. http://pdf.usaid.gov/pdf_docs/Pnadn456.pdf. Accessed 26 Jan 2017.

Weichselgartner, J. 2016. Vulnerability as a concept in science and practice. In Atlas of vulnerability and resilience - Pilot version for Germany, Austria, Liechtenstein and Switzerland, ed. A. Fekete, and G. Hufschmid, 18-21. Cologne and Bonn: University of Applied Sciences and University of Bonn.

Weichselgartner, J., and I. Kelman. 2015. Geographies of resilience: Challenges and opportunities of a descriptive concept. Progress in Human Geography 39(3): 249-267.

White, G.F., R.W. Kates, and I. Burton. 2001. Knowing better and losing even more: The use of knowledge in hazards management. Environmental Hazards 3: 81-92.

Wisner, B., P. Blaikie, T. Cannon, and I. Davis. 2004. At risk: Natural hazards, people's vulnerability and disasters, 2nd edn. London and New York: Routledge.

Wisner, B., J.C. Gaillard, I. Kelman. 2012. Framing disaster. In The Routledge handbook of hazards and disaster risk reduction, ed. B. Wisner, J.C. Gaillard, and I. Kelman, 18-33. London: Routledge.

Wong, P. 2012. Impacts, recovery and resilience of Thai tourist coasts to the 2004 Indian Ocean Tsunami. Geological Society London Special Publications 361: 127-138.

Zahari, R.K., R.N. Raja Ariffin, M.Z. Asmawi, and A. Nadhrah Ibrahim. 2013. Impacts of the 2004 Tsunami: Preparedness of the Malaysian coastal communities. Asia Pacific International Conference on Environment-Behaviour Studies. Procedia Social and Behavioral Sciences 105: 569-576. 